\title{
La figura de la gestación por sustitución*
}

\author{
Federico Notrica** \\ Francisco Cotado ${ }^{* * *}$ \\ Patricio Jesús Curti
}

\section{RESUMEN}

El presente trabajo desarrolla la figura de la gestación por sustitución comenzando por su conceptualización, sus acepciones y caracteristicas principales. Se coloca especial atención a los derechos humanos de las personas involucradas en este procedimiento, entre ellas, la gestante, los comitentes y el niño que nace. Las ventajas de obtener una regulación legal por sobre la prohibición expresa o el silencio de la ley, analizándose las distintas estrategias judiciales en Argentina. Finalmente, se explicitan las caracteristicas de los proyectos de ley recientemente presentados en el ámbito legislativo argentino para impulsar una regulación integral de la gestación por sustitución.

PALABRAS CLAVE: Gestación por sustitución, Bioética, Derechos Humanos, Argentina.

\begin{abstract}
This work develops the substitute gestation figure, starting with its conceptualization, meanings and main characteristics. Particular attention is paid to human rights of the persons involved in this procedure, among them, the pregnant woman, the principals and the child who is born. The advantages of obtaining a legal regulation on the express prohibition or the silence of the law, analyzing the different judicial strategies in Argentina. Finally, we explain the characteristics of bills recently presented in the Argentine legislative level to boost an integral regulation of the substitute gestation.
\end{abstract}

KER WORDS: substitute gestation, bioethics, human rights, Argentina

* Artículo recibido el 7 de septiembre de 2016 y aceptado el 14 de noviembre de 2016

** Docente de Familia y Sucesiones de la Universidad de Buenos Aires, Argentina. fedenotrica@gmail.com.

*** Abogado (Universidad Nacional de Mar del Pata),Argentina. franciscocotado@gmail.com.

**** Docente de Familia y Sucesiones de la Universidad de Buenos Aires, Argentina. patriciojcurti@gmail.com 


\section{SUMARIO}

1. Nociones introductorias

2. La regulación como una necesidad y el aporte de los derechos humanos

3. La situación de la gestación por sustitución en Argentina

4. Conclusiones

\section{Nociones introductorias}

En esta época, la gestación por sustitución (GS) es uno de los institutos más debatidos en el derecho de familia y el campo de la bioética, en virtud de que las sociedades modernas readecuaron las formas de vivir en familia y las normas no han dado una respuesta lógica a situaciones determinadas complejas. ${ }^{1}$

Estas cuestiones produjeron un encuentro entre la bioética y el derecho, específicamente, con el derecho de familia. Se trata de un encuentro indestructible y necesario para analizar las nuevas realidades.

En este trabajo se buscará conceptualizar la GS, marcar las diferentes acepciones y características principales, para vislumbrar los conflictos que trae aparejada. Luego, se pondrá especial atención a los derechos de todas las personas que forman parte de estos procedimientos. Finalmente: a través de la observación de los grandes conflictos suscitados en la jurisprudencia argentina, se analizarán los distintos proyectos de ley que se presentaron en el Congreso argentino.

Tal como ha expresado Casado, desde el nacimiento de esta nueva disciplina, ambas - bioética y derecho- caminan unidas. La implicación entre el derecho y la bioética es de carácter intrínseco y, así como la contribución de aquél es fundamental para ésta, las aportaciones del análisis bioético se deben considerar de extrema utilidad para el derecho a la hora de elucidar los problemas suscitados por la biotecnología. Ambas disciplinas comparten una misma finalidad: el respeto y la promoción de los derechos humanos reconocidos. ${ }^{2}$

Estos cambios se dieron en las relaciones familiares debido a una "revolución reproductiva". Como postula la dra. Eleonora Lamm, se habla en estos términos "porque estas técnicas separan la reproducción humana de la sexualidad. Es decir, hoy en día, y gracias a las TRHA, es posible la reproducción sin

\footnotetext{
' Corral Dueñas, Francisco, "La filiación derivada de técnicas de reproducción asistida, de Marina Pérez Monge", Revista Crítica de Derecho Inmobiliario, No. 677, 2003, pp. 1954.

2 Herrera, Marisa y Lamm, Eleonora, "Técnicas de reproducción humana asistida", en Bergel, Salvador Dario y otros, Bioética en el nuevo Código civil y Comercial de la Nación, Buenos Aires, La Ley, 2015, p. 295.
} 
sexo, y esta separación entre el fenómeno reproductor humano y el ejercicio de la sexualidad viene a plantear una problemática que desborda las estructuras jurídicas existentes y actúa como punto de partida para un gran número de cambios. $^{3}$

Para comenzar este camino, es menester aclarar algunas ideas. Una de las primeras definiciones de este instituto fue la de Phyllis Coleman, quien pensando a una familia matrimonial compuesta por personas de distinto sexo, expresó que la Gs o la maternidad subrogada -como la denominó- es:

una aplicación novel de la técnica de la inseminación artificial que resulta en el nacimiento de una criatura con un nexo biológico unilateral a la pareja infértil. La gestante es una mujer fértil que conviene, mediante contrato, se la insemine artificialmente con el semen de un hombre casado con otra mujer, gestar el niño y darla a luz o procrearla. Una vez nacido el niño, la gestante o suplente renuncia su custodia a favor del padre biológico y, además, termina todos sus derechos de filiación sobre el niño para que la esposa del hombre con cuyo semen fue inseminada la adopte. ${ }^{4}$

Las técnicas de reproducción asistida (TRHA) han evolucionado de manera asombrosa, considerando a la Gs. Coleman, como otros de su época, la definió como una técnica de baja complejidad en la que la gestante era inseminada. Hoy, por el contrario, podemos asegurar que en la mayoría de los países donde se regula, se utilizan técnicas de alta complejidad para que, justamente, el óvulo no sea de la persona gestante sino de quien resulte comitente o de quien sea donante. ${ }^{5}$

Para analizar esta figura, debemos definirla, en líneas generales, como una forma de reproducción asistida por medio de la cual una persona, denominada gestante, acuerda con otra, o con una pareja, denominada comitente, gestar un embrión con el objetivo de que la persona nacida tenga vínculos jurídicos de filiación con este o estos últimos.

\footnotetext{
${ }^{3}$ LAMm, ElEONORA, Gestación por sustitución: ni maternidad subrogada ni alquiler de vientres, Barcelona, Universidad de Barcelona, 2013, p. 17.

${ }^{4}$ Coleman, Phillys, "Surrogate motherhood: analysis of the problems and suggestions for solutions", Tenessee Law Review, No. 50, 1982, pp. 71-118.

${ }^{5}$ Cabe señalar que existen diferentes modalidades de gestación por sustitución. En la tradicional o total, la gestante aporta no sólo la gestación, sino también sus gametos. En la gestacional o parcial, la gestante aporta la gestación, pero no sus óvulos; estos serán aportados por la comitente, en caso de que pueda hacerlo, o por una donante.
} 
La gestación por sustitución -término que se ajusta mejor a la realidad- ${ }^{6}$ es generalmente conocida como maternidad subrogada o alquiler de vientre, pero creemos necesario aclarar los motivos por los cuales no deben usarse esas acepciones. $^{7}$

No se debe llamar "maternidad subrogada" por cuanto la maternidad engloba una realidad mucho más extensa que la gestación. En estos casos, la maternidad no se subroga, sino la gestación, es decir, se gesta para otros. La gestante no tiene la voluntad de tener un hijo; lo que hace es justamente gestar para que el otro sea padre o madre. Por ende, se debe dilucidar la división entre maternidad y gestación. ${ }^{8}$

En los casos en que se denomina "alquiler de vientre", se colma de un contenido patrimonial a una figura, que debería ser, a nuestro modo de considerarla, altruista y solidaria, sin perjuicio de las compensaciones que pudieran llegar a otorgarse. ${ }^{9}$

Como ya sabemos, el conflicto no radica sólo en su conceptualización, sino en que posee dicotomías extremas en cuanto a lo legal y lo ético.

Desde el campo jurídico, podemos observar que para la determinación de la filiación en el campo de las TRHA el elemento relevante es la voluntad. "No sólo en cuanto causa eficiente última e infungible (para ese nacimiento concreto), sino porque los demás elementos, biológicos o genéticos, pueden ser sustituidos [...] Lo que nadie puede suplir en cada caso en concreto, para un determinado nacimiento, es el acto de voluntad [...]" ${ }^{10}$ Esto claramente condice la noción de voluntad procreacional.

Para entender el principio de la voluntad en la Gs, podemos decir que ésta es "la intención de querer engendrar un hijo con material genético propio, acudiendo a la implantación del embrión en el vientre de una tercera persona para su gestación y alumbramiento posterior. Sucede que esta tercera persona care-

${ }^{6}$ Cfr. Souto Galván, Beatriz, "Aproximación al estudio de la gestación de sustitución desde la perspectiva del bioderecho", Foro. Revista de Ciencias Jurídicas y Sociales, España, No. 1, 2005, pp. 283-284.

${ }^{7}$ Hay otras acepciones en el derecho comparado como: alquiler de útero, donación temporaria de útero, gestación por cuenta de otro, gestación subrogada, madres de alquiler.

${ }^{8}$ Véase CANDAL, LEILA, "La maternidad intervenida. Reflexiones en torno a la maternidad subrogada", Revista Redbioética, No. 1, 2010, pp. 174-188.

${ }^{9}$ En doctrina se debate acerca de la modalidad económica o altruista de la Gs. Así, se puede leer que no debe ser de modalidad económica, pues implicaría una cosificación o comercialización del cuerpo humano y permitiría a la gestante el intercambio de un derecho inalienable por dinero, es decir, la comercialización de su capacidad de gestación. En otros casos, se expresa que la as debe ser económica porque los comitentes contratan los servicios de una mujer para gestar un bebé, que será luego el hijo de los primeros.

${ }^{10}$ Rivero Hernández, Francisco, "La investigación de la mera relación biológica en la filiación derivada de fecundación artificial", 1987 en La filiación a finales del siglo XX. Problemática planteada por los avances científicos en materia de reproducción humana, Madrid, Trivium, 1988. 
ce de voluntad; falta el elemento central que atribuye o determina la filiación en las técnicas de reproducción humana asistida: la voluntad procreacional". ${ }^{11}$ Es decir, serán progenitores, del niño o niña que nazca, quienes hayan expresado su consentimiento previo, informado y libre antes de la realización de algún tratamiento de TRHA, entre ellos la Gs. A partir de ahí, se generarán todos los derechos y deberes que surgen con el vínculo filial, dejando de lado la aplicación del principio clásico mater semper certa est. ${ }^{12}$

A pesar de ser una definición que refleja el objetivo de la figura, creemos que la voluntad procreacional se antepone a la idea de engendrar a un hijo con material genético propio de la pareja. Si así fuese, dejaríamos a un universo de personas que, solas o en pareja, no poseen material genético en condiciones adecuadas para ser utilizado. Por esta razón, hacemos extensiva la noción de que la Gs es la intención o el deseo de tener un hijo, por medio de una tercera persona para que esta última realice la gestación del niño o la niña.

Gracias a los avances científicos, la maternidad y paternidad dejan de considerarse una relación de filiación basada en reduccionismo genetista o biológico. Por el contrario, se impone el establecimiento de una realidad no genética sino socio-afectiva, determinada por la aportación del elemento volitivo. ${ }^{13}$

\section{La regulación como una necesidad y el aporte de los derechos humanos}

Frente a una realidad insoslayable como el fenómeno de la GS, nos preguntamos: ¿Cuál es la solución jurídica que mejor se ajusta al esquema propuesto por la doctrina internacional de los derechos humanos?

Partiremos de distintos soportes clave. En primer lugar, del concepto "familia” en consonancia con los numerosos instrumentos internacionales que la tratan, a través de cláusulas que marcan su protección. En particular con los alcances del artículo 17 de la Convención Americana sobre Derechos Humanos, el cual ha sido oportunamente interpretado por la Corte Interamericana de Derechos Humanos. ${ }^{14}$

\footnotetext{
1 Kemelmajer de Carlucci, Aida, Lamm, Eleonora, Herrera, Marisa, Gestación por sustitución en Argentina. Inscripción judicial del niño conforme a la regla de la voluntad procreacional, Argentina, La Ley, 2013, p. 3.

${ }^{12}$ Vale tener en cuenta que el principio mater semper certa est, según el cual madre es siempre cierta, porque es ella la mujer que da a luz, se encuentra en crisis. Sin embargo, pocas normativas en el derecho comparado tienen regulada la figura de la gestación por sustitución.

${ }^{13}$ LAMm, ELEONORA, Gestación por sustitución: ni maternidad subrogada ni alquiler de vientres, Barcelona, Universidad de Barcelona, 2013, p. 44.

${ }^{14}$ Véase Corte Interamericana de Derechos Humanos, "Caso Fornerón e hija vs. Argentina", sentencia de 27 de abril
} 
La Constitución de la Nación Argentina, en su artículo 14 bis, refiere a la protección integral de la familia, de manera amplia e indeterminada. Dentro de esta conceptualización, se vislumbra la idea de que todo tipo de familia es reconocido y protegido, de forma inclusiva y plural, por nuestro ordenamiento jurídico. Entre los distintos tipos de familia, encontramos tanto a la familia tradicional, es decir, la familia matrimonial, heterosexual, como a las familias compuestas por matrimonios entre personas del mismo sexo, uniones convivenciales, entre personas de igual o distinto sexo, familias monoparentales, ensambladas, entre otras.

En segundo lugar, se considera el derecho a fundar una familia como un derecho humano. Éste se menciona en la Declaración de los Derechos Humanos, el Pacto Internacional de los Derechos Civiles y Políticos, entre otros, y se debe ejercer de forma libre y responsable. ${ }^{15}$

Asimismo, "la noción de familia no es única, ni unívoca, sino es plural, temporal, eminentemente mutable, y decididamente sociológica. El derecho debe ir acompañando esos cambios, a modo de no quedar decididamente atrasado en las pautas y conceptos dados en el plano social". ${ }^{16}$

Concatenar estos dos ejes implica que la persona sola o pareja, donde al menos un integrante tiene falencias estructurales, físicas, médicas o genéticas para poder concebir hijos, podrá recurrir al método que supere la situación obstructiva, desde una visión integral y respetando la diversidad.

En este sentido, Minyersky ha dicho que "las diferentes y múltiples formas familiares que existen en nuestra sociedad, si bien son el resultado de años de gestación, también son el resultado del reconocimiento de la autonomía de la voluntad de los individuos, no sólo sobre su propia vida, sino sobre su vida familiar. Cada individuo, más allá del derecho positivo del lugar en el que vive, decide formar su familia del modo en que lo considere apropiado". ${ }^{17}$

de 2012. Disponible en http://corteidh.or.cr/docs/casos/articulos/seriec_242_esp.pdf

${ }^{15}$ En este esquema y para una mejor comprensión del enunciado, cabe señalar la idea de "derechos reproductivos" que se consolidó a nivel universal a partir de la Conferencia Internacional sobre la Población y el Desarrollo de Naciones Unidas (CIPD), realizada en El Cairo en 1994 y la Cuarta Conferencia Mundial de la Mujer, Beijing 1995. Estos instrumentos establecieron, entre otras cuestiones, que los derechos reproductivos abarcaban ciertos derechos humanos que ya estaban reconocidos en las leyes nacionales, en los documentos internacionales y en otros documentos pertinentes de las Naciones Unidas aprobados por consenso. Incluian, también el derecho a adoptar decisiones relativas a la reproducción sin sufrir discriminación, coacciones, ni violencia. Abarcan no sólo la forma "natural", sino también las nuevas tecnologias reproductivas.

${ }^{16}$ MuÑIz, JAVIER, "El concepto de familia en el Derecho Comparado", en Fernández, Silvia (Dir.), Tratado de derechos de niños, niñas y adolescentes, tomo 1, Buenos Aires, Abeledo-Perrot, 2015, p. 645.

${ }^{17}$ MinYersky, Nelly, "El impacto del Proyecto del Código Civil y Comercial de la Nación en instituciones del Derecho de Familia", p. 79. Disponible en http://www.derecho.uba.ar/publicaciones/pensar-en-derecho/revistas/0/el-impac- 
Por último, un precepto internacional clave: el interés superior del niño. Este principio, además de integrar el orden público internacional, debe ser una consideración primordial a la que se atenderá en todas las medidas que se tomen. ${ }^{18}$ En tal sentido, deberá admitirse el reconocimiento de niños y niñas nacidos a través de estas técnicas de reproducción humana asistida, sea a nivel interno o cuando la relación jurídica sea internacional. Asimismo, cuando corresponda aplicar el derecho extranjero, si ello redunda en el interés superior de los niños.

La doctrina utilizó este principio rector expresándose de la siguiente manera:

Regular la gestación por sustitución es la solución que mejor satisface el interés superior del niño, porque desde el mismo momento del nacimiento, el niño encuentra una familia que lo quiere; además, él mismo no hubiese existido de no haber mediado el acuerdo. El interés superior del niño se asegura limitando el poder de las partes, y esto sólo puede hacerse a través de la regulación legal de estos convenios. Ese interés exige contar con un marco legal que proteja al niño, le brinde seguridad jurídica y le garantice una filiación acorde a la realidad volitiva. ${ }^{19}$

En el mismo sentido, el derecho a la identidad del niño nacido es un derecho humano que traspasa todo el ordenamiento jurídico. Por la gran importancia que tiene para nuestra sociedad, es dable destacar que, si bien debe tener su filiación determinada con quienes otorgaron su voluntad procreacional, podrían aplicarse los artículos 563 y 564 del Código Civil y Comercial de la Nación. Estos referidos al derecho al acceso a la información del donante, y en este caso también a la gestante, a quien se le encomendó gestar para otro y hacer que un niño naciera.

Otro punto importante dentro de la categoría de derechos humanos es la importancia que tiene el principio de igualdad y no discriminación. Éste se relaciona con el derecho a fundar una familia, en contexto de igualdad y libertad, sin condicionamientos de ningún tipo, especialmente, en cuanto a la orientación sexual de la persona sola o los miembros de la pareja.

\footnotetext{
to-del-proyecto-del-codigo-civil-y-comercial-de-la-nacion-en-instituciones-del-derecho-de-familia.pdf ${ }^{18}$ Conforme al artículo 3.1 de la Convención sobre los Derechos del Niño.

${ }^{19}$ Lamm, Eleonora, "Gestación por sustitución. Realidad y derecho", InDret, Revista para el análisis del derecho, BarceIona, julio 2012. Disponible en www.indret.com/code/getPdf.php?id=1578\&tpdf=909_es.pdf
} 
Dicho esto, podemos traer a colación que "por todo lo expuesto, y desde la consagración constitucional-convencional del derecho humano a fundar una familia con su inmediata derivación en los derechos reproductivos, es que la igualdad debe ser real, reconocida por la ley, y sin discriminación hacia un sector de la población que debido a problemas de salud (infertilidad) o a su orientación sexual, queda al margen de la posibilidad de procrear". ${ }^{20}$

En este contexto, se recuerda lo expresado en la Conferencia Internacional sobre la Población y el Desarrollo, celebrada en El Cairo, en 1994, donde Argentina asistió como Estado participante y se esgrimieron ciertos principios directamente aplicables al tema de las TRHA. Al respecto, se sostuvo que "toda persona tiene derecho al disfrute del más alto nivel posible de salud física y mental. Los Estados deberían adoptar todas las medidas apropiadas para asegurar, en condiciones de igualdad entre hombres y mujeres, el acceso universal a los servicios de atención médica, incluidos los relacionados con la salud reproductiva, que incluye la planificación de la familia y la salud sexual”.

Por su parte, la Corte IDH, en el caso Artavia Murillo, ha señalado que

el principio de derecho imperativo de protección igualitaria y efectiva de la ley y no discriminación determina que los Estados deben abstenerse de producir regulaciones discriminatorias o que tengan efectos discriminatorios en los diferentes grupos de una población al momento de ejercer sus derechos. [...] Este concepto implica que una norma o práctica aparentemente neutra tiene repercusiones particularmente negativas en una persona o grupo con unas características determinadas. [...] Es obligación de los Estados propender por la inclusión de las personas con discapacidad por medio de la igualdad de condiciones, oportunidades y participación en todas las esferas de la sociedad, con el fin de garantizar que las limitaciones anteriormente descritas sean desmanteladas. Por tanto, es necesario que los Estados promuevan prácticas de inclusión social y adopten medidas de diferenciación positiva para remover dichas barreras.

En última instancia, el derecho a usar y gozar del avance y los beneficios de la ciencia y la tecnología se convierte en una pieza clave en esta historia, porque "el acceso a las TRHA involucra el derecho a formar una familia, el derecho a ha-

\footnotetext{
${ }^{20}$ Notrica, Federico, Melón, Pablo y González, Andrea, "La gestación por sustitución como una realidad que no puede ser silenciada". Disponible en http://www.pensamientocivil.com.ar/system/files/2015/11/Doctrina2253.pdf
} 
cerse del desarrollo de la ciencia médica o los beneficios de la biotecnología y en un primer momento, el derecho a la salud centrado en la noción de infertilidad". ${ }^{21}$

Todo individuo puede proyectar la idea de procrear suscribiendo al uso de la ciencia o, en términos del Pacto Internacional de Derechos Económicos, Sociales y Culturales, "gozando de los avances de la ciencia". ${ }^{22}$

Esta idea contribuye al desarrollo personal del ser humano y le permite sentirse digno porque sabe que, en definitiva, puede fundar una familia. La familia, ese elemento tan fundamental dentro de las sociedades, ${ }^{23}$ puede ser ahora una real e igualitaria posibilidad de construcción para todos.

Hechas las consideraciones anteriores, podemos decir que son tres las respuestas posibles ante el dilema legal que se plantea:

- La prohibición absoluta de la Gs y los efectos jurídicos sobre la filiación del niño o niña. Principalmente, las limitaciones normativas, son discriminatorias por tres razones: a) desde el punto de vista económico: es sabido que esta práctica se realiza en muchos países del mundo y de esta manera las personas que cuentan con recursos económicos viajan al exterior y se someten a esta compleja técnica fuera de las fronteras nacionales. Las prohibiciones legales, entonces, resultan accesibles sólo para quienes pueden afrontarlas; b) en materia de incapacidad física: se vincula con las mujeres que no pueden gestar, por ejemplo, por carecer de útero, es decir una incapacidad de concebir o de llevar a término un embarazo; c) en materia de género: la gs representa la única opción que tiene una pareja homosexual, compuesta por dos hombres, o un hombre solo, atento a que, por razones biológicas sean incapaces de concebir y gestar un hijo propio.

- El silencio de la ley. Una opción tan peligrosa como común, la cual siempre ha mostrado un camino de incertidumbres, según las aristas de los casos resueltos.

Como se ha expresado, los avances biomédicos ligados a los cambios so161 ciales y culturales de las últimas décadas han potenciado el acceso a estas téc-

\footnotetext{
${ }^{21}$ Herrera, Marisa y De la Torre, Natalia, "De identidades y familias. Aportes al debate sobre matrimonio entre personas del mismo sexo en el derecho argentino", en Revista lustel, Madrid, 2013.

${ }^{22}$ Pacto Internacional de Derechos Económicos, Sociales y Culturales, artículo 15, b) Gozar de los beneficios del progreso científico y de sus aplicaciones.

${ }^{23}$ Cfr. Declaración Universal de Derechos Humanos (artículo 16, párrafo tercero): "La familia es el elemento natural y fundamental de la sociedad y tiene derecho a la protección de la sociedad y del Estado".
} 
nicas, generando en el campo jurídico la necesidad de reformular los principios tradicionales. En consecuencia, es imperiosa la necesidad de que el discurso jurídico se ocupe de regularlas. El silencio legal encausa interpretaciones discordantes que provocan resoluciones disímiles por parte de nuestros magistrados, sumergiendo a los justiciables en la inseguridad jurídica. ${ }^{24}$

- La instauración de un régimen jurídico adecuado que regule y ordene tales prácticas y sus consecuencias sobre la filiación. Perfilarse en esta alternativa representa la posibilidad de brindar respuestas y soluciones a un medio reproductivo cada vez más frecuente a nivel, no solo nacional, sino también regional y universal. Sin dudas, la opción de la regulación legal disminuye los conflictos. El problema no está es la práctica en sí misma, sino la inexistencia de un marco normativo que permita controlar y establecer criterios para llevarla a cabo atendiendo a los intereses de todas las partes involucradas: la persona gestante, la o las personas comitentes y el niño o niña, fruto de este procedimiento.

Desde la puja existente entre la vulneración de derechos humanos que representa la prohibición expresa de la Gs, pasando por el vacío legal, hasta llegar a la regulación, nos encontramos ante esta última posibilidad como una manera de que muchas parejas o personas solas puedan llevar adelante su proyecto vital de formar una familia, mediante normas posibilitadoras y desde una óptica igualitaria.

Dicho lo anterior, sumamos que, basándonos en el principio de la realidad, estamos obligados a pensar acerca de la necesidad de una regulación sistémica y no menos compleja, por la gran cantidad de casos en los que las parejas tienen como única alternativa la utilización de la GS para consagrar su derecho a fundar una familia.

La regulación no sólo visibiliza, sino que protege a todas las partes intervinientes $\mathrm{y}$, al hacerlo, se debe tener en miras el derecho a procrear y a formar una familia, como derecho fundamental. Además, esta planificación va asociada a la libertad reproductiva que incluye como elementos constitutivos la elección de procrear, con quién y por qué medios; la elección del contexto social en que la reproducción tiene lugar; la elección de cuándo reproducirse y la elección de cuántos hijos tener. ${ }^{25}$

\footnotetext{
${ }^{24}$ FamÁ, Maria Victoria, "Maternidad subrogada. Exégesis del derecho vigente y aportes para una futura regulación", La Ley, julio 2011, p. 1.

${ }^{25}$ FamÁ, Marí VIctoria, "La infertilidad y el acceso a las técnicas de reproducción asistida como un derecho humano",
} 
También, debemos tener en miras a los niños o niñas nacidos con el procedimiento:

regular la gestación por sustitución es la solución que mejor satisface el interés superior del niño, porque desde el mismo momento del nacimiento el niño encuentra una familia que lo quiere; además, él mismo no hubiese existido de no haber mediado el acuerdo. El interés superior del niño se asegura limitando el poder de las partes, y esto sólo puede hacerse a través de la regulación legal de estos convenios. Ese interés exige contar con un marco legal que proteja al niño, le brinde seguridad jurídica y le garantice una filiación acorde a su realidad volitiva”. ${ }^{26}$

\section{La situación de la gestación por sustitución en Argentina}

Sin dudas, la Gs encuentra cada vez más asidero en la jurisprudencia argentina, teniendo absolutamente todas las sentencias con resultado favorable a la figura. ${ }^{27}$

No puede pasarse por alto que en el Anteproyecto del Código Civil y Comercial de la Nación -que entró en vigencia en Argentina el 1 de agosto de 2015-, la Comisión Redactora había incluido a la Gs en el originario artículo 562, determinando el proceso, los requisitos y efectos que alcanzaban a las personas involucradas. ${ }^{28}$

A pesar de ello, la norma proyectada fue suprimida por ser la figura jurídica que más voces encontradas había generado en el ámbito de las relaciones de familia. Ahora bien, el vacío legal sigue siendo un problema debido a que, a pesar de la jurisprudencia favorable, no puede negarse que los tiempos de la justicia y la consecuente incertidumbre en la que obliga a reposar a los implicados durante el trayecto del proceso, son violatorios del derecho del niño a su identidad, a la vida privada y familiar, a la salud sexual y reproductiva de sus progenitores.

Por otra parte, se requiere de un proceso judicial para que determine los vínculos de los niños con sus progenitores. Cuando los niños al nacer no cuentan con su debida inscripción tienen vedados sus derechos a la salud y a la educación, entre otros. Lo cierto es que, aunque el niño viva con quienes lo

\footnotetext{
La Ley, Argentina, No. 144, junio 2009, p. 3.

${ }^{26}$ LAMm, ElEONORA, "Gestación por sustitución. Una valiente y valiosa sentencia", La Ley, Argentina, diciembre 2015, p. 1.

${ }^{27} \mathrm{~A}$ la fecha, son catorce los fallos emitidos y todos ellos favorables a reconocer la filiación con los comitentes.

${ }^{28}$ Artículo 562 del Anteproyecto del Código Civil y Comercial de la Nación Argentina: Gestación por sustitución.
} 
desearon y ellos actúen como sus progenitores, el vínculo jurídico no estará establecido hasta que se dicte una sentencia que así lo determine.

Tampoco parece razonable que una familia, para constituirse como tal ante los ojos de la ley, deba atravesar todo este proceso sin mayor certeza que la eventual voluntad del magistrado para hacer lugar a su derecho constitucional, convencional, a fundar una familia.

Frente a esta realidad, existen varias estrategias jurídicas para cuestionar el principio general "madre cierta es" y lograr que la justicia reconozca la filiación del niño nacido con quien o quienes proyectaron el deseo de ser progenitores. En este sentido, dichas estrategias pueden dividirse en tres grandes grupos: a) autorización judicial previa; b) impugnación de la maternidad, la cual se encuentra en cabeza de la gestante; c) acción declarativa de certeza o solicitud judicial para lograr la inscripción del nacido en cabeza de los comitentes.

Con la autorización judicial previa, se busca que el magistrado interviniente autorice la transferencia del embrión al cuerpo de la gestante y ordene la inscripción, una vez nacido el niño o la niña, a favor de los comitentes.

En los casos en que se utilizó la inscripción directa del nacimiento a nombre de los comitentes, el niño ya había nacido (ex post facto). Fue importante para los jueces intervinientes que la voluntad procreacional coincidiera con quienes habian aportado los gametos, es decir, quienes tenían un vínculo genético con el recién nacido. Por esta razón podemos afirmar otra vez que, frente a estos casos, la voluntad procreacional se ve desvirtuada. Su sentido es justamente otro, podrá coincidir, pero no es lo fundamental. Lo que sí importa es el deseo de ser ellos los progenitores.

Otra vía procesal dentro de esta estrategia fue la presentación de una acción declarativa de certeza, debido a que los niños ya habían sido inscriptos. Entonces se ordenó la inmovilización de las actas de nacimiento y la inscripción en nuevas actas donde los niños debían figurar como hijos de quienes habían expresado su voluntad de ser padres.

La otra estrategia fue solicitar la impugnación de la maternidad de la persona gestante por no ser la "madre biológica". Luego, reclamar la maternidad de la comitente, desplazando a la primera del estado de madre y emplazando en ese carácter a la segunda.

Resulta oportuno señalar que ésta fue la primera que se planteó, y algunos de esos fallos fueron dictados en vigencia del Código Civil anterior. Al determinar la maternidad con el parto, admitía en su artículo 261 la posibilidad de impugnar la maternidad "por no ser la mujer la madre del hijo que pasa por suyo". 
Luego de efectuar estas comparaciones, doctrinarios y juristas se manifestaron en las xxv Jornadas Nacionales de Derecho Civil en la Comisión número 6 de Familia, "Identidad y Filiación”. En ésta se propuso que "Se debe regular la Gs en una Ley Especial conforme el criterio del artículo 562 del Anteproyecto del Código Civil y Comercial de la Nación" - unanimidad-y "La ley especial de GS debe hacer hincapié en la protección de todas las personas intervinientes" -mayoría-.

Acorde a estos lineamientos se halla un proyecto de ley presentado por la entonces senadora Laura Montero, en el año 2015, ${ }^{29}$ el cual, de no ser tratado, perderá su estado parlamentario al finalizar este año legislativo. Ante esta situación, el 21 de septiembre del 2016, se presentaron dos nuevos proyectos de ley los cuales versan sobre el mismo tema, pero presentan diferencias sustanciales dignas de mencionar.

Por un lado, se encuentra el proyecto presentado por una organización no gubernamental (oNG) que defiende los derechos de la diversidad sexual, llamada Federación Argentina, Lesbianas, Gays, Bisexuales y Transexuales (FALGBT). ${ }^{30}$ Aunque este proyecto denomina la "gestación solidaria", su articulado nada dice sobre el carácter no lucrativo de la gestación. Pero expresa que este procedimiento de Gs se llevará a cabo a través de un acuerdo entre privados, cuyas partes serán la gestante (quien gesta para otro) y el comitente (quien tendrá vínculo filial con la persona que nazca).

A pesar de que este procedimiento exige la formalización del centro médico autorizado y posteriormente la protocolización ante escribano público o autoridad sanitaria, los consentimientos para prestar la voluntad procreacional son actos personalísimos. Por ello, un acuerdo en conjunto de todas las partes no podría suplir ese requisito que establece la ley, para garantizar los derechos de todos los involucrados en las TRHA. Además, se fija una serie de obligaciones que tiene la persona gestante y se contempla la posibilidad de que los comitentes puedan exigirle a la gestante que interrumpa su embarazo durante las primeras catorce semanas cumplidas de gestación.

Por otro lado, se encuentra el proyecto de ley que presentaron en conjun165 to la Sociedad Argentina de Medicina Reproductiva (Samer), las ong Concebir, Súmate a dar vida, Abrazo por dar vida y 100\% Diversidad y Derechos. ${ }^{31}$ Con

\footnotetext{
${ }^{29}$ Montero, Laura Gisela, Proyecto de ley No. 2574/15, 2015. Disponible en http://www.senado.gov.ar/parlamentario/ comisiones/verExp/2574.15/S/PL

${ }^{30}$ Victimas de violencia institucional por motivo de identidad de género. Expediente 5700-D-2016. Disponible en http://www.diputados.gov.ar/proyectos/proyectoTP.jsp?id=185737

${ }^{31}$ Gestación por sustitución. Expediente 5759-D-2016. Disponible en http://www.diputados.gov.ar/proyectos/pro-
} 
la diversidad de actores para su elaboración, se aborda la temática de manera interdisciplinaria, ya que se trata de una figura que compromete no sólo al campo de la diversidad sexual, sino también a otros usuarios, y a la comunidad científica. En su articulado se puede observar de manera clara el objetivo de este proyecto: no sólo la regulación de la técnica, sino determinar su alcance, los derechos y las relaciones jurídicas de la Gs y su proceso judicial.

Así, el mayor énfasis estará en proteger a todos los intervinientes, fundamentalmente a la gestante y al niño o niña que nacerá. Se opta por un proceso de autorización judicial previa donde el magistrado deberá garantizar que se cumplan los requisitos que la ley exige. Esto para dar curso a la implementación de la GS, controlando que no se vulnere el derecho de ninguno de los intervinientes, incluida la persona por nacer.

Se expresa el carácter no lucrativo de la Gs, pero sin desconocer el esfuerzo por el que va a atravesar la gestante. Por tal motivo, se estipula una compensación económica a fin de cubrir todos los gastos necesarios, para que el proceso se lleve adelante de manera correcta. Esto está pensado en traslados, estudios médicos, licencias y demás circunstancias a las que tenga que hacer frente la persona gestante durante el embarazo. Incluso el proyecto hace eco de lo que ocurre en otras partes del mundo y, para evitar el conocido "turismo reproductivo", exige que tanto la gestante como los comitentes tengan un plazo mínimo de cinco años de residencia ininterrumpida en el país.

En este sentido, tomando real dimensión de la vulnerabilidad en que muchas veces se encuentran las mujeres al ser reclutadas por un sistema sin controles estatales, y con el fin de evitar que otros agentes lucren con el deseo y derecho de las personas de formar una familia, el proyecto exige que exista un vínculo afectivo previo entre los comitentes y la gestante, y determina un máximo de dos veces de gestar para otro. Asimismo, determina la intervención de un cuerpo interdisciplinario que debe dictaminar en favor de la autorización peticionada.

Introduce modificaciones al Código Penal para sancionar al funcionario público o profesional de la salud que facilite, promueva o de cualquier modo intermedie en la transferencia de un embrión a una persona para que actúe como gestante sin la correspondiente autorización judicial o sin que haya transcurrido el plazo de un año desde la fecha de la autorización judicial. También propone una sanción para quien intermedie entre una persona o una pareja deseosa de acoger un niño y una persona que acepte llevar a término su

yectoTP.jsp?id=190090 
gestación con el fin de entregárselo. Por último, modifica también la ley nacional 26.862 de acceso integral, para que el sistema de salud incorpore a la GS como tratamiento.

Como vimos, los proyectos presentados tienen concepciones muy distintas y acuden a estrategias disímiles para intentar regular esta técnica de reproducción. Sin embargo, ambos se proponen llenar el vacío que hoy en día tiene la legislación argentina y que necesita de una pronta y adecuada respuesta para salvaguardar los derechos de quienes recurren a la Gs. Por otra parte, fueron distintas las soluciones que adoptaron en los casos de Gs realizadas en el extranjero.

$\mathrm{Al}$ tratar estos casos debemos considerar que se presentan dos problemas distintos. En primer lugar, los conflictos a resolver cuando los comitentes desean desplazar al niño del país donde nació hacia el Estado de su residencia. ${ }^{32}$ En segundo lugar, el problema que sucede una vez que el niño se encuentra en el Estado de residencia de los comitentes y se busca regularizar la situación legal del niño, respecto a su filiación y, en algunos casos, su nacionalidad.

Uno de los conflictos se promovió en el caso que tramitó ante el Juzgado Contencioso Administrativo y Tributario número 5 de la Ciudad Autónoma de Buenos Aires, llamado por los medios de comunicación el "Caso Tobías”.

Un matrimonio, conformado por dos hombres argentinos, realizó un proceso de gestación por sustitución en la India, pero existía una incertidumbre acerca de cómo inscribir a su hijo nacido por este tipo de procesos en aquel país, pues éste no otorga nacionalidad a los hijos de extranjeros que nacen en su territorio. Es verdad que a los niños nacidos mediante la gestación por sustitución se les extiende un certificado de nacimiento en el cual figura el nombre del padre aportante del gameto masculino, mientras la madre aparece como "madre subrogante o madre sin estado".

El certificado, en ningún caso, otorga nacionalidad india. Por ello, si al niño que iba a nacer en unos meses no se le concedía la nacionalidad argentina, quedaría apátrida. En virtud de ello, el matrimonio argentino solicitó la garantía de inscripción del niño a favor de ambos y el pasaporte para poder viajar de regreso al país. Así entonces, el jefe de la Sección Consular, de la Embajada Argentina en India, comunicó el dictamen efectuado por la Dirección General de Asuntos Jurídicos respecto de los nacimientos operados bajo la figura de la gestación por sustitución. Ésta determinó que no era posible dar curso a la inscripción de una partida de nacimiento en la cual no figurara el nombre de la

\footnotetext{
${ }^{32}$ Hay que tener en cuenta los principios de ius sanguini y ius solis que prevalecen en cada país para determinar la nacionalidad de cada una de las personas nacidas.
} 
madre, dado que ello no se ajustaba a lo dispuesto en el artículo 36 inciso c) de la ley 26.413. Esta ley impone que dicha inscripción debe contener el nombre y apellido de la madre y el padre, o la madre y su cónyuge, excepto si se trata de un hijo extramatrimonial, quien se inscribe sólo con el nombre de la madre. ${ }^{33}$

Frente a ello, el matrimonio inició una acción de amparo para que el Ministerio de Relaciones Exteriores entregara la documentación correspondiente del niño y reconociera la paternidad en ellos dos con base en la noción de voluntad procreacional y la identidad genética.

Se efectuaron reuniones con el Ministerio de Relaciones Exteriores, el cual manifestó que el consulado ejerce funciones delegadas por el Registro Civil de la Ciudad Autónoma de Buenos Aires. Por ende, requerían una autorización expresa de dicho organismo. Así, se solicitó una acción declarativa de certeza en sede administrativa. En virtud de ello, el Registro Civil informó que el Ministerio de Relaciones Exteriores tiene facultades propias para inscribir nacimientos, defunciones y matrimonios en sus consulados, cuando lo requieran argentinos nativos o naturalizados. Por tal razón, no era necesaria la autorización para que se otorgara lo solicitado por el matrimonio. Esto era que el niño fuera inscripto como hijo de ambos, reconociendo la coparentalidad.

Como resultado, la justicia hizo lugar a la acción de amparo autorizando al Registro Civil a inscribir el nacimiento del niño cuando la Embajada Argentina en la India así lo solicitara, y a favor de los dos hombres miembros del matrimonio. Tal decisión se fundamentó en el derecho a la no discriminación por razón de orientación sexual, el derecho a la identidad, la protección de las relaciones familiares y el principio rector del interés superior del niño.

Después de este caso se presentaron otros en los cuales también se debatía la cuestión registral de niños nacidos por gestación por sustitución en el exterior, por parte de comitentes argentinos que pretendían ingresar al país una vez que el niño naciera. Se obtuvo una respuesta judicial afirmativa.

Es importante destacar lo que expresa la jurisprudencia al momento de analizar las diferencias de acuerdo con la orientación sexual de los miembros de la pareja, al expresar que

mientras una pareja heterosexual y una conformada por dos mujeres pueden inscribir a nombre de ambos cónyuges al hijo nacido bajo las técnicas de reproducción asistida, no se reconoce el mismo derecho

\footnotetext{
${ }_{33}$ Bergel, Salvador Dario; Flah, Lliy Rosa; Herrera, Marisa; Lamm, Eleonora; Wierzba, Sandra; "Bioética en el Código Civil y Comercial de la Nación", La Ley, Buenos Aires, 2015, p. 405 y ss.
} 
a una pareja de hombres, quienes biológicamente no tienen otra alternativa que recurrir a una mujer para poder concretar su deseo de ser padres. Si tanto las parejas heterosexuales como las homosexuales conformadas por mujeres tienen derecho a inscribir a nombre de ambos cónyuges al hijo concebido gracias a las técnicas de reproducción asistida sin que se tenga en cuenta el elemento biológico, prohibir o impedir, u obstaculizar del modo que sea esta facultad cuando la pareja está conformada por dos hombres implicaría un cabal desconocimiento de los derechos de igualdad y no discriminación de esas personas. En la Constitución local se 'reconoce y garantiza el derecho a ser diferente', no admitiendo discriminaciones que tiendan a la segregación por razones o por pretexto de 'orientación sexual' (artículo 11).

Entre las disposiciones de Derecho Internacional Privado contenidas en el Código Civil y Comercial, el artículo 2634 incluye a la filiación otorgada en el extranjero consecuente del empleo de técnicas de reproducción humana asistida (TRHA), por lo cual la GS se encuentra allí contemplada, aunque no de manera explícita. ${ }^{34}$

En virtud de ello, la Dirección de Asistencia Jurídica del Ministerio de Relaciones Exteriores y Culto de la Nación ha dictaminado acerca al alcance de dicha norma del Código Civil y Comercial, manifestando que:

De la mencionada norma, resultaría la obligatoriedad de reconocer toda filiación constituida de acuerdo al derecho extranjero, en beneficio del interés superior del niño, incluso aquellas filiaciones surgidas de una maternidad subrogada. Ello, independientemente de que el contrato de maternidad por subrogación se encuentre o no regulado por nuestro régimen legal. Debería analizarse la posibilidad de revisar las instrucciones que actualmente se imparten en materia de inscripción de nacimientos ocurridos en el exterior como consecuencia de una maternidad subrogada. También deberá revisarse la posibilidad de tramitar nacionalidades por opción en estos casos, ya sea por trámite consular o judicial.

Por ello, los proyectos mencionados hacen alusión a este artículo, lo cual no deja margen para cuestionar si la Gs se encuentra efectivamente dentro de las TRHA, pues esta nueva ley saldaría esa discusión.

${ }^{34}$ Código Civil y Comercial, Artículo 2634. Reconocimiento de emplazamiento filial constituido en el extranjero. 


\section{Conclusiones}

Esta figura tiene un fin primordial en la vida de las personas: tener un hijo y formar la familia que tanto añoran. Muchos derechos se dejarían de vulnerar y de condicionar si se regulara la Gs en una ley integral que tuviera en miras, como el último proyecto relatado, los derechos de todas las partes intervinientes.

Lo que se busca es alentar un marco jurídico que privilegie y represente una garantía para el ejercicio de los derechos, que respete y promueva el derecho de las personas a construir paternidades y maternidades libres y responsables. Asimismo que se reconozca la pluralidad y diversidad que existe en nuestra sociedad y se deje de invisibilizar una realidad que pide a gritos nombre y cuerpo, para asegurar el derecho humano de toda persona a fundar $\mathrm{y}$ vivir en familia.

\section{Bibliografía}

Bergel, Salvador Darí; Flah, Lily Rosa; Herrera, Marisa; lamm, Eleonora; Wierzba, SANDRA; "Bioética en el Código Civil y Comercial de la Nación", La Ley, Buenos Aires, 2015, p. 405 y ss.

Candal, Leila, "La maternidad intervenida. Reflexiones en torno a la maternidad subrogada”, Revista Redbioética, No. 1, 2010, pp. 174-188.

Coleman, Phillys, "Surrogate motherhood: analysis of the problems and suggestions for solutions”, Tenessee Law Review, No. 50, 1982, pp. 71-118.

Corral DueÑas, Francisco, "La filiación derivada de técnicas de reproducción asistida, de Marina Pérez Monge”, Revista Crítica de Derecho Inmobiliario, No. 677, 2003, pp. 1954.

Corte Interamericana de Derechos Humanos, “Caso Fornerón e hija vs. Argentina”, sentencia de 27 de abril de 2012. Disponible en http://corteidh.or.cr/docs/casos/ articulos/seriec_242_esp.pdf

FAmÁ, María Victoria, "La infertilidad y el acceso a las técnicas de reproducción asistida como un derecho humano", La Ley, Argentina, No. 144, junio 2009, p. 3.

FamÁ, María Victoria, "Maternidad subrogada. Exégesis del derecho vigente y aportes para una futura regulación”, La Ley, julio 2011, p. 1.

Gestación por sustitución. Expediente 5759-D-2016. Disponible en http://www.diputados.gov.ar/proyectos/proyectoTP.jsp?id=190090

Herrera, Marisa y De la Torre, Natalia, "De identidades y familias. Aportes al debate sobre matrimonio entre personas del mismo sexo en el derecho argentino", en Revista Iustel, Madrid, 2013.

Herrera, Marisa y Lamm, Eleonora, "Técnicas de reproducción humana asistida”, en Bergel, Salvador Darío y otros, Bioética en el nuevo Código civil y Comercial 
de la Nación, Buenos Aires, La Ley, 2015, p. 295.

Kemelmajer de Carlucci, Aída, Lamm, Eleonora, Herrera, Marisa, Gestación por sustitución en Argentina. Inscripción judicial del niño conforme a la regla de la voluntad procreacional, Argentina, La Ley, 2013, p. 3.

Lamm, Eleonora, "Gestación por sustitución. Realidad y derecho", InDret, Revista para el análisis del derecho, Barcelona, julio 2012. Disponible en www.indret.com/code/getPdf.php?id=1578ctpdf=909_es.pdf

LAMm, ELEONORA, Gestación por sustitución: ni maternidad subrogada ni alquiler de vientres, Barcelona, Universidad de Barcelona, 2013, p. 17.

LAMm, ElEONORA, "Gestación por sustitución. Una valiente y valiosa sentencia”, La Ley, Argentina, diciembre 2015, p. 1.

Minyersky, Nelly, "El impacto del Proyecto del Código Civil y Comercial de la Nación en instituciones del Derecho de Familia”, p. 79. Disponible en http:// www.derecho.uba.ar/publicaciones/pensar-en-derecho/revistas/0/el-impacto-del-proyecto-del-codigo-civil-y-comercial-de-la-nacion-en-instituciones-del-derecho-de-familia.pdf

Montero, Laura Gisela, Proyecto de ley No. 2574/15, 2015. Disponible en http:// www.senado.gov.ar/parlamentario/comisiones/verExp/2574.15/S/PL

MuÑIZ, JAVIER, "El concepto de familia en el Derecho Comparado", en Fernández, Silvia (Dir.), Tratado de derechos de niños, niñas y adolescentes, tomo 1, Buenos Aires, Abeledo-Perrot, 2015, p. 645.

Notrica, Federico, Melón, Pablo y González, Andrea, "La gestación por sustitución como una realidad que no puede ser silenciada”. Disponible en http://www. pensamientocivil.com.ar/system/files/2015/11/Doctrina2253.pdf

Rivero Hernández, Francisco, "La investigación de la mera relación biológica en la filiación derivada de fecundación artificial”, 1987 en La filiación a finales del siglo XX. Problemática planteada por los avances científicos en materia de reproducción humana, Madrid, Trivium, 1988.

Souto GalvÁn, Beatriz, "Aproximación al estudio de la gestación de sustitución desde la perspectiva del bioderecho”, Foro. Revista de Ciencias Jurídicas y Sociales, España, No. 1, 2005, pp. 283-284.

Víctimas de violencia institucional por motivo de identidad de género. Expediente 5700-D-2016. Disponible en http://www.diputados.gov.ar/proyectos/proyectoTP.jsp?id=185737 
172 